\title{
OUTCOMES OF BABIES ON BUBBLE CPAP ADMITTED IN SNCU (LEVEL II) AT ACSR GMC, NELLORE, INDIA
}

\author{
Menni Chowdary Babu1, C. Lakshmi Prasanna², P. Satya Prakash ${ }^{3}$
}

1Associate Professor, Department of Paediatrics, ACSR Government Medical College, Nellore.

${ }^{2}$ Assistant Professor, Department of Paediatrics, ACSR Government Medical College, Nellore.

${ }_{3}^{3}$ Assistant Professor, Department of Paediatrics, ACSR Government Medical College, Nellore.

ABSTRACT

\section{BACKGROUND}

India contributes to one-fifth of the global live births and of the 25 million babies born in India every year 1 million die. India alone contributes to $25 \%$ of neonatal mortality around the world. The aim of the study is to assess the morbidity profile of babies admitted in SNCU requiring Bubble CPAP and their outcomes on Bubble CPAP in terms of complications, duration of BCPAP, discharges and deaths on BCPAP.

\section{MATERIALS AND METHODS}

50 neonates were on CPAP during the study period. All data were collected from recorded case sheets as inborn or outborn admissions, sex, gestational age, weight for gestation, referral centre, age at presentation, indications for BCPAP, duration of BCPAP, complications encountered and outcome of these babies on BCPAP.

Study Design- It is a prospective observational study observed during July 2016 to Dec 2016 (6 months).

\section{RESULTS}

Of the 50 babies on BCPAP, males were $50 \%$ and females were $50 \%$. Most of the babies on BCPAP in SNCU were preterm 32 (64\%) than term 18 (36\%). As per birth weight, most of the admitted babies were between $1500-2500$ gms (82\%). In terms of morbidity, most of the babies on BCPAP were due to RDS/ HMD 28 (56\%) followed by Birth Asphyxia 7 (14\%), MAS/ Pneumonia 4 (8\%), Sepsis 4 (8\%), Apnoeas 3 (6\%), CHD 2 (4\%) and other causes 2 (4\%). Outcomes- Out of 50 babies on BCPAP 10 babies (20\%) got discharged, LAMA 12 (24\%), referral to higher centre for advanced ventilation $3(6 \%)$ and deaths were 25 (50\%). The major morbidity for mortality was due to RDS/ HMD 13 (52\%) followed by Birth Asphyxia 5 (20\%), Pneumonia 1 (4\%), Sepsis 2 (8\%), Apnoeas (8\%) and Others $1(4 \%)$.

\section{CONCLUSION}

Available evidence from observational studies suggests that CPAP is a safe and effective mode of therapy in preterm neonates with respiratory distress in resource poor countries. It reduces the in-hospital mortality and the need for ventilation, thereby minimising the need for up-transfer to a referral hospital. But in spite of this evidence the mortality of babies on CPAP in our SNCU is still high and this signifies more training of manpower, critical monitoring of babies on CPAP and need for surfactant for better outcomes of the babies on BCPAP.

\section{KEYWORDS}

Outcomes, BCPAP, Mortality.

HOW TO CITE THIS ARTICLE: Babu MC, Prasanna CL, Prakash PS. Outcomes of babies on Bubble CPAP admitted in SNCU (level II) at ACSR GMC, Nellore, India. J. Evolution Med. Dent. Sci. 2018;7(05):619-622, DOI: 10.14260/jemds/2018/140

\section{BACKGROUND}

India contributes to one-fifth of the global live births and of the 25 million babies born in India every year 1 million die. India alone contributes to $25 \%$ of neonatal mortality around the world. As per the National Family Health Survey- 3 reports, current Neonatal Mortality Rate (NMR) in India is 39 per 1000 live births, neonatal deaths accounts for nearly $77 \%$ of all infant deaths $(57 / 1000)$ and nearly half of under-five child deaths (74/1000). ${ }^{1}$ As per the report sheet published in the Lancet, the major direct causes of neonatal mortality are preterm birth (27\%), infection (26\%), asphyxia (23\%), congenital anomalies (7\%) and others (7\%). ${ }^{2}$

'Financial or Other Competing Interest': None.

Submission 02-12-2017, Peer Review 12-01-2018,

Acceptance 18-01-2018, Published 29-01-2018.

Corresponding Author:

Dr. C. Lakshmi Prasanna,

Assistant Professor, Department of Paediatrics,

ACSR Government Medical College, Nellore.

E-mail: chowdarymenni99@gmail.com

DOI: $10.14260 /$ jemds $/ 2018 / 140$
The rate of the neonatal mortality varies widely among the different states of India, ranging from 11 per 1000 live births in Kerala to 48 per 1000 live births in Uttar Pradesh. ${ }^{3}$

In Telangana and Andhra Pradesh, roughly 25 and 29 infants die for every 1,000 live births respectively. The two Telugu-speaking states have the highest Neonatal Mortality Rate (NMR) in South India. In Kerala, the NMR is below 10. In Tamilnadu it is between 10 and 15 and in Karnataka the number of deaths is 15 to 20 infants for 1,000 live births. ${ }^{4}$ The State target is to bring down NMR rate to less than 10 by 2030 . This target is going to be achieved by setting up Special New Born Care Units (SNCUs) in each district and equipped with Bubble CPAPs to decrease the early neonatal deaths, which are mostly due to prematurity related deaths. This has resulted in showing improvement on the NMR front as against during united Andhra Pradesh. ${ }^{5}$ Available evidence from observational studies suggest that CPAP is a safe and effective mode of therapy in preterm neonates with respiratory distress in resource poor countries. ${ }^{6}$ It reduces the in-hospital mortality and the need for ventilation, thereby minimising the 
need for up-transfer to a referral hospital. So this study is done to assess the morbidity profile of babies admitted in SNCU requiring Bubble CPAP and their outcomes on Bubble CPAP in terms of complications, duration of BCPAP, discharges and deaths on BCPAP in our SNCU (Level II).

\section{MATERIALS AND METHODS}

This study is a prospective observational study of medical records carried out in the neonatal intensive care unit (SNCU) of the Department of Paediatrics, ACSR GMC, Nellore for 6 months from July 2016 to Dec 2016 (6 months).

\section{Inclusion Criteria}

All neonates $<28$ days admitted to SNCU and started on Bubble CPAP for supportive care were included in the study. Preterm babies with Anderson Silverman's score of $>6$ and term babies with Downes' Score $>6$ were started on BCPAP.

\section{Exclusion Criteria}

1. Babies with severe MAS with pneumothorax.

2. Babies with lethal congenital malformations on BCPAP for only supportive care.

After obtaining permission of Head of the Institute, data of all the admitted babies started on Bubble CPAP were recorded by analysing all the case sheets from the records section. Data was collected as inborn or outborn, admission, sex, gestational age, weight for gestation, referral centre, age at presentation, indications for BCPAP, duration of BCPAP, complications encountered and outcomes of discharge, lama referral and death were recorded. Primary disease was considered as final diagnosis for indication of BCPAP. Even the baby developed complications of primary disease or having more than one disease. WHO definitions were used for Term, Preterm, Low Birth Weight (LBW), Very Low Birth Weight (VLBW), Extreme Low Birth Weight (ELBW) and congenital malformation. Meconium aspiration syndrome was diagnosed on the basis of history, clinical and radiological findings. Sepsis was diagnosed by clinical and appropriate lab screening tests.

\section{RESULTS}

During the period from July 2016 to Dec 2016 (6 months), total 50 babies were supported on BCPAP in SNCU. Inborn babies were 27 (54\%) and outborn babies were 23 (46\%). The Male and Female ratios were equal, i.e. 50\% each. The No. of Preterm babies were more than the term babies, 32 (64\%) vs. 18 (36\%). As per birth weight most babies were < 2500 gms, of which $<1500$ gms contributed to $42 \%$ and 1500 gms to 2500 gms $40 \%$. In terms of morbidity, most of the babies on BCPAP were due to RDS/ HMD 28 (56\%) followed by Birth Asphyxia 7 (14\%), MAS/ Pneumonia 4 (8\%), Sepsis 4 (8\%), Apnoeas 3 (6\%), CHD 2 (4\%) and other causes 2 (4\%), Tables $1,2,3,4,5$.

\begin{tabular}{|c|c|c|c|}
\hline Gender & Inborn & Outborn & Percentage \\
\hline Males & 12 & 13 & $50 \%$ \\
\hline Females & 15 & 10 & $50 \%$ \\
\hline Total & $\mathbf{2 7}$ & $\mathbf{2 5}$ & $\mathbf{1 0 0 \%}$ \\
\hline \multicolumn{4}{|c|}{ Table 1. Gender Distribution } \\
\hline
\end{tabular}

\begin{tabular}{|c|c|c|c|c|}
\hline Month & Inborn & Outborn & Total & $\%$ \\
\hline July & 3 & 4 & 7 & $14 \%$ \\
\hline August & 6 & 8 & 14 & $28 \%$ \\
\hline September & 5 & 5 & 10 & $20 \%$ \\
\hline October & 6 & 3 & 8 & $16 \%$ \\
\hline November & 3 & 2 & 6 & $12 \%$ \\
\hline December & 4 & 1 & 5 & $10 \%$ \\
\hline Total & $\mathbf{2 7}$ & $\mathbf{2 3}$ & $\mathbf{5 0}$ & $\mathbf{1 0 0 \%}$ \\
\hline \multicolumn{5}{|c}{ Table 2. Admission Profile } \\
\hline
\end{tabular}

\section{SEX DISTRIBUTION}

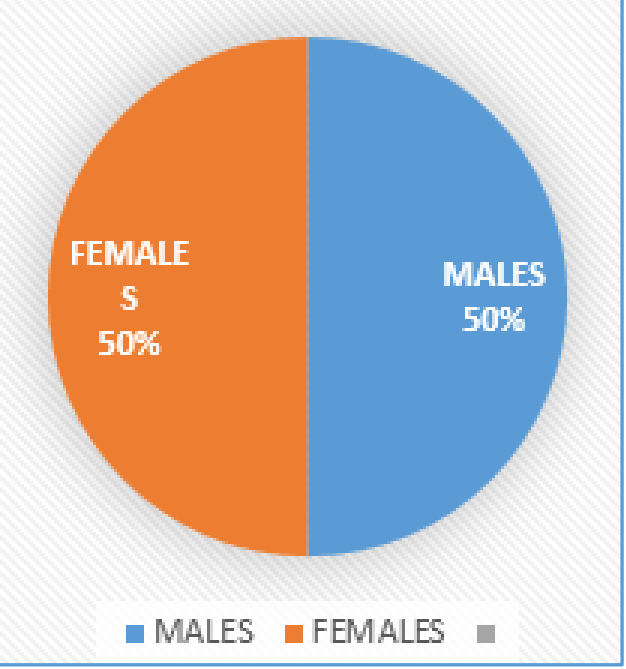

Figure 1

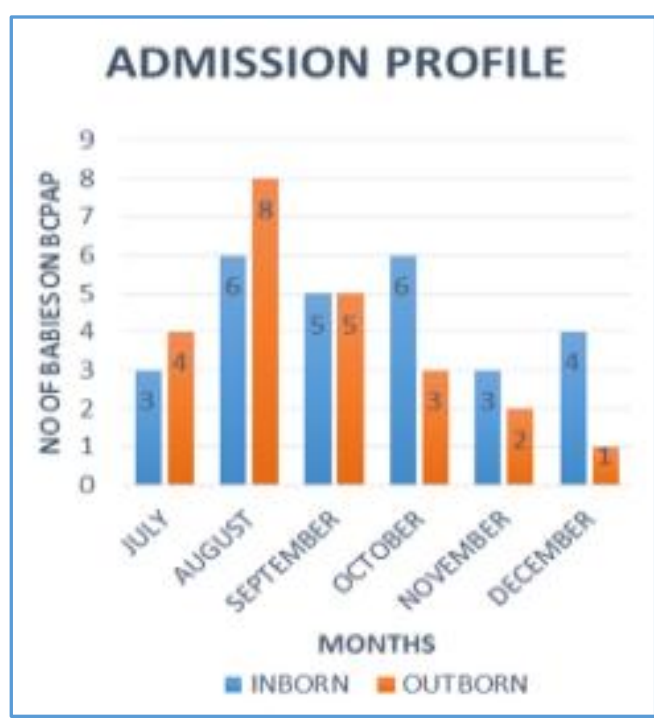

Figure 2

\begin{tabular}{|c|c|c|c|}
\hline Gestation & Inborn & Outborn & Percentage \\
\hline Preterm & 17 & 15 & $64 \%$ \\
\hline Term & 10 & 8 & $36 \%$ \\
\hline Total & $\mathbf{2 7}$ & $\mathbf{2 3}$ & $\mathbf{1 0 0} \%$ \\
\hline \multicolumn{2}{|r|}{ Table 3. Gestation Age Distribution } \\
\hline
\end{tabular}

\begin{tabular}{|c|c|c|c|}
\hline Weight & Inborn & Outborn & Percentage \\
\hline$>2500$ gms & 5 & 4 & $18 \%$ \\
\hline $1500-2500$ gms & 9 & 12 & $42 \%$ \\
\hline$<1500$ gms & 13 & 7 & $40 \%$ \\
\hline Total & $\mathbf{2 7}$ & $\mathbf{2 3}$ & $\mathbf{1 0 0 \%}$ \\
\hline \multicolumn{4}{|c}{ Table 4. Birth Weight } \\
\end{tabular}




\begin{tabular}{|c|c|c|c|c|}
\hline Morbidity & Inborn & Outborn & Total & $\mathbf{\%}$ \\
\hline RDS/ HMD & 15 & 13 & 28 & $56 \%$ \\
\hline $\begin{array}{c}\text { Birth } \\
\text { asphyxia }\end{array}$ & 3 & 4 & 7 & $14 \%$ \\
\hline Sepsis & 2 & 2 & 4 & $8 \%$ \\
\hline Apnoeas & 2 & 1 & 3 & $6 \%$ \\
\hline CHD & 2 & 0 & 2 & $4 \%$ \\
\hline Others & 1 & 1 & 2 & $4 \%$ \\
\hline Total & $\mathbf{2 7}$ & $\mathbf{2 3}$ & $\mathbf{5 0}$ & $\mathbf{1 0 0 \%}$ \\
\hline \multicolumn{5}{|c}{ Table 5. Morbidity for CPAP } \\
\hline
\end{tabular}

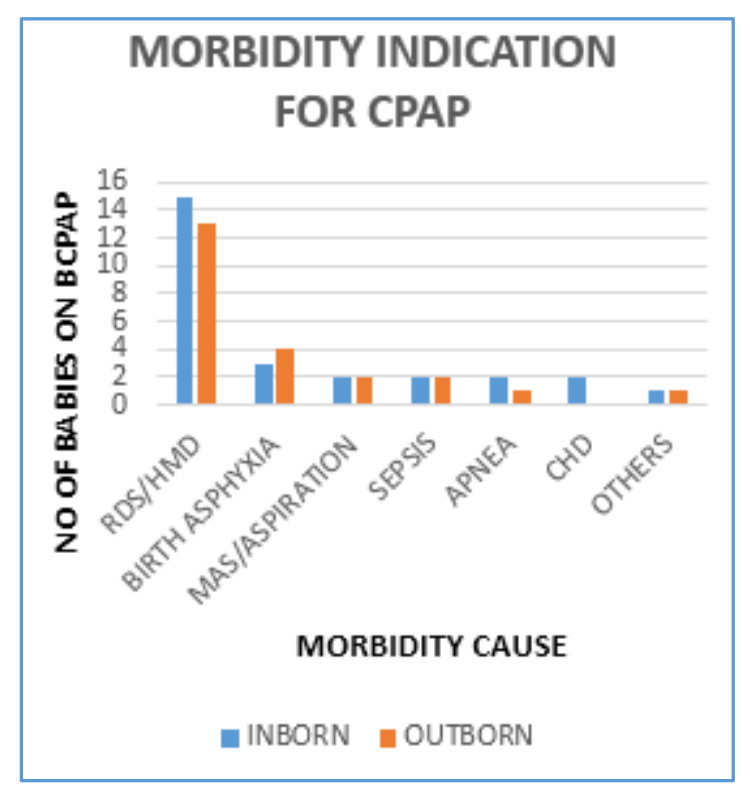

Figure 3

\section{Outcomes}

Out of 50 babies on BCPAP 10 babies (20\%) got discharged, LAMA $12(24 \%)$, referral to higher centre for advanced ventilation $3(6 \%)$ and deaths were 25 (50\%).

\begin{tabular}{|c|c|c|c|c|}
\hline Outcome & Inborn & Outborn & Total & Percentage \\
\hline Discharge & 4 & 6 & 10 & $20 \%$ \\
\hline Lama & 8 & 4 & 12 & $24 \%$ \\
\hline Referral & 2 & 1 & 3 & $6 \%$ \\
\hline Death & 14 & 11 & 25 & $50 \%$ \\
\hline Total & $\mathbf{2 7}$ & $\mathbf{2 3}$ & $\mathbf{5 0}$ & $\mathbf{1 0 0 \%}$ \\
\hline \multicolumn{7}{|c|}{ Table 6. Outcomes on CPAP } \\
\hline
\end{tabular}

\section{Outcomes}

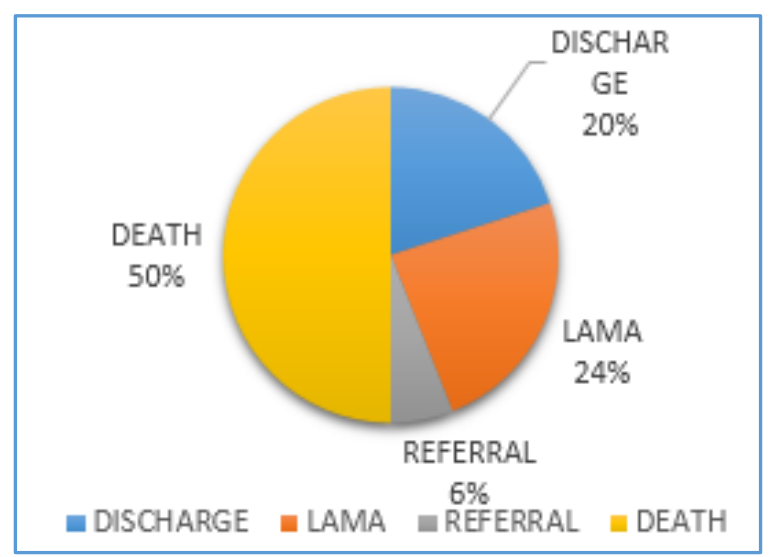

Figure 4

\section{Mortality}

The major morbidity for mortality was due to RDS/ HMD 13 (52\%) followed by Birth Asphyxia 5 (20\%), then Pneumonias $1(4 \%)$, sepsis $2(8 \%)$, Apnoeas (8\%) and others 1 (4\%), Tables $7,8$.

\begin{tabular}{|c|c|c|c|c|}
\hline Birth Weight & Inborn & Outborn & Total & \% \\
\hline$>2500$ gms & 2 & 1 & 3 & $12 \%$ \\
\hline 1500-2500 gms & 3 & 7 & 10 & $40 \%$ \\
\hline$<1500$ gms & 9 & 3 & 12 & $48 \%$ \\
\hline \multicolumn{6}{|c|}{ Table 7. Mortality on CPAP as Per Weight } \\
\hline
\end{tabular}

\begin{tabular}{|c|c|c|c|c|}
\hline Morbidity & Inborn & Outborn & Total & $\%$ \\
\hline RDS/ HMD & 8 & 5 & 13 & $52 \%$ \\
\hline Birth Asphyxia & 2 & 3 & 5 & $20 \%$ \\
\hline $\begin{array}{l}\text { Aspiration/ } \\
\text { Pneumonias }\end{array}$ & 1 & 0 & 1 & $4 \%$ \\
\hline Sepsis & 1 & 1 & 2 & $8 \%$ \\
\hline Apnoeas & 1 & 1 & 2 & $8 \%$ \\
\hline CHD & 1 & 0 & 1 & $4 \%$ \\
\hline Others & 0 & 1 & 1 & $4 \%$ \\
\hline Total & 16 & 10 & 25 & $100 \%$ \\
\hline
\end{tabular}

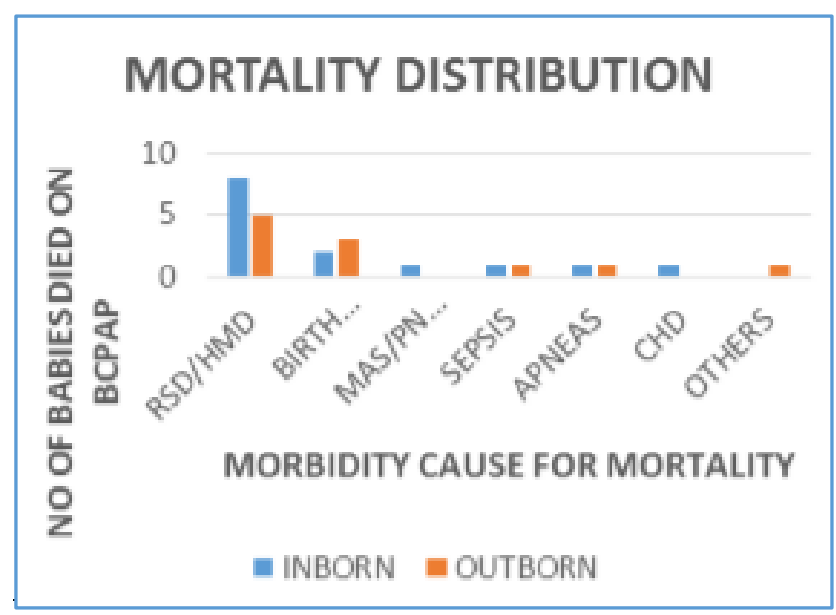

Figure 5

\section{DISCUSSION}

Continuous Positive Airway Pressure (CPAP) is a wellestablished mode of respiratory support in preterm newborns. Good enough evidence is there to support CPAP as low costeffective intervention to reduce the morbidity burden of RDS in preterm babies. CPAP vs. no CPAP (Hood oxygen)- Metaanalysis evaluating CPAP against head box oxygen showed that CPAP use reduced the overall rate of mortality [RR 0.52 (95\% CI 0.32, 0.87)] and the rate of the combined outcome of death or assisted ventilation [RR 0.70 (95\% CI 0.55, 0.88)] 8. Use of CPAP has also shown to decrease the need for up-transfers to higher centres. ${ }^{7}$ The introduction of CPAP in a level II special newborn care unit significantly reduced the need for uptransfers as compared to pre-CPAP epoch, especially in very low birth weight (VLBW) and preterm infants. ${ }^{8}$

During the study period analysis, 50 babies admitted in SNCU were treated with BCPAP. Both males and females were $50 \%$ each and among these outborns were $23(42 \%)$ and inborn 27 (58\%). The no. of Preterm babies 32 (64\%) were 
more than term babies $18(36 \%)$. Most of the babies were $<2500$ gms, 41 (82\%). The morbidity cause for CPAP was similar to many studies, as most of the babies requiring supportive care by CPAP were Preterm and LBWs with RDS. NNPD data showed similar findings of morbidities for admission and need for respiratory support. ${ }^{9}$

Outcomes- Out of 50 babies on BCPAP 10 babies (20\%) got discharged, LAMA 12 (24\%), Referral to higher centre 3 (6\%) and Deaths were 25 (50\%). Most of the discharged babies were $>2000$ gms and most of the deaths were under 2500 gms $22(82 \%)$. The major cause of mortality was RDS 13 (52\%) followed by birth Asphyxia 5 (20\%). According to the Cochrane review use of CPAP was associated with lower rates of failed treatment by about $30 \%$, overall mortality by $50 \%$ and mortality in babies with birth weight above 1500 grams by as much as $75 \%$. Verder et al and Reininger et al showed that CPAP along with surfactant (by InSurE) as compared to CPAP alone in symptomatic preterm neonates with RD decreases the need of mechanical ventilation. ${ }^{10}$ This is in contrast to our studies, as mortality on BCPAP was $50 \%$ and discharges were only $20 \%$. This needs more introspection and care of the babies on CPAP and augment the need for surfactant for better outcome of babies in SNCUs.

\section{CONCLUSION}

Available evidence from observational studies suggest that CPAP is a safe and effective mode of therapy in preterm neonates with respiratory distress in resource poor countries. It reduces the in-hospital mortality and the need for ventilation, thereby minimising the need for up-transfer to a referral hospital. But in spite of this evidence, the mortality of babies on BCPAP in our SNCU is still high and this signifies more training of manpower, care and monitoring of babies on CPAP and need for surfactant for better outcomes of the babies on BCPAP.

\section{REFERENCES}

[1] Sankar MJ, Neogi SB, Sharma J, et al. State of newborn health in India. Journal of Perinatology 2016;36:S3-S8.

[2] The Million Death Study Collaborators, Bassani D, Kumar R, et al. Causes of neonatal and child mortality in India: a nationally representative mortality survey. Lancet 2010;376(9755):1853-60.

[3] Gupta N, Saini SS, Murki S, et al. Continuous positive airway pressure in preterm neonates: an update of current evidence and implications for developing countries. Indian Pediatrics 2015;52(4):319-28.

[4] Nitiayog report. 2017. http://niti.gov.in/content/infant-mortality-rate-imr1000-live-births.

[5] NFH3reporthttp://rchiips.org/NFHS/factsheet_NFHS4. html 2014-2015. http://www.newbornwhocc.org/pdf/nnpd_report_20 02 2003.PDF.

[6] http://cfw.ap.nic.in/pdf/Infant\%20Mortality\%20Rat. pdf.

[7] Niswade A, Zodpey SP, Ughade S, et al. Neonatal morbidity and mortality in tribal and rural communities in central India. Indian Journal of Community Medicine 2011;36(2):150-8.

[8] Gauchan E, Basnet S, Koirala DP, et al. Clinical profile and outcome of babies admitted to Neonatal Intensive Care Unit (NICU). Journal of Institute of Medicine 2011;33(2):1-5.

[9] Prasad V, Singh N. Causes of morbidity and mortality in neonates admitted in Government Medical college, Haldwaniin, Kumaun region, Uttarkhaand, India. JBPS 2011;8(8):1-4.

[10] Shah GS, Yadav S, Thapa A, et al. Clinical profile and outcome of neonates admitted to Neonatal Intensive Care Unit (NICU) at a Tertiary Care Centre in Eastern Nepal. J Nepal Paediatr Soc 2013;33(3):177-81. 